\title{
Reading Readers
}

Jennifer M. Miskec and Annette Wannamaker, eds. 2016. The Early Reader in Children's Literature and Culture. New York: Routledge. 256 pp. ISBN: 9781-138-93168-8

DOI: 10.21066/carcl.libri.2016-05(02).0015

As reading is an important aspect of growing up and learning, every child has to learn how to do it. At the beginning of their reading journey, children are usually exposed to picturebooks which parents read to them and later they start to read books by themselves. But what happens in between? How do children learn to read books by themselves?

The essay collection The Early Reader in Children's Literature and Culture deals with books especially written and designed for children who are beginning to read independently, called Early Readers, and it is the first volume to consider this category. In the book, the editors argue that Early Readers deserve more attention than they have so far received, as they play a very important role in the process of learning how to read. They also note that very little academic thought has been devoted to Early Readers because they are usually seen as "transitional and cheaply produced works of paraliterature" (1). According to the editors, Early Readers deserve much more scholarly attention since they "shape a child's relationship with the written world" (2). In order to give Early Readers the attention they deserve, editors Jennifer Miskec and Annette Wannamaker gathered original essays that examine the books in this category from different points of view. These essays have been divided into four sections, each exploring one aspect of Early Readers.

In the introduction, the editors familiarise readers with the topic and define Early Readers as children's first opportunity to engage with a piece of literature on their own and the first books children are able to read by themselves. They also note that throughout the collection of essays they use the terms "Early Readers" (capitalised) and "early readers" (lower case) to make the distinction between the books and the children who read them.

The first section, "History", deals with the origins of Early Readers. At the beginning, Ramona Caponegro lists numerous labels often given to Early Readers: primer, reader, Easy Reader, beginning book, transitional book, first chapter book, tot series book, early graphic novel. She also describes some of the first Early Readers, such as the New England Primer, Rollo Learning to Read, Bow-Wow and Mew-Mew, The Boxcar Children, The Cat in the Hat, and Little Bear. Besides investigating the first Early Readers and their characteristics and success, this chapter also addresses the topic of creating and marketing Early Reader picturebooks which, according to Rebekah Fitzsimmons, occupy a central place in the Early Reader category.

Section two, entitled "Aesthetics and Form", demonstrates the multidisciplinarity of Early Readers and how and why the stories in them are told. As Karen Coats emphasises, reading should be seen as a repetitive act, so "each book has to end with an invitation to return rather than an expression of finality" (68). Consequently, many Early Readers lack a global closure, obstacles and problems remain unresolved, and they lack the typical ending we are used to. On the other hand, Gretchen Papazian deals with story beginnings and notes that reading involves motivation and a reason to read, so Early Readers are required to begin in that way: with motivation. Arnold Lobel's book Frog and Toad Are Friends is 
given as an example of a book which begins in such a way. When it comes to the way of reading Early Readers, Hade and Hudock describe and praise Mo Willems's Elephant and Piggie series in which reading is not limited just to reading words written on the page, but also includes visual language clues which help young readers understand the story.

The third section, "Culture", examines how cultural aspects are manifested in Early Readers. While most children's books deliver nice and warm stories, there are also some which are full of horror and scary plots. In her essay, Katherine Slater examines the Early Reader In a Dark, Dark Room, and notes that "fear and pleasure are not mutually exclusive categories" (125). On the contrary, children can still function and learn how to read when exposed to fear and excitement presented in the stories. Another cultural concern is addressed in Michelle Beisell Heath's essay which considers some of the ways in which Early Readers may trouble traditional value systems, while focusing on normalising "weird girl characters to demonstrate identity conflicts of childhood, and frequently girlhood in particular" (141). Helen Bittle writes about a similar topic in her discussion of normalising the kind of free-range, risky plays in stories for children, while Sarah Park Dahlen explores the issue of misuse and stereotyping of Native American culture.

The final, fourth section, "Global Contexts", puts Early Readers in an international context. In this chapter, the authors list and describe various Early Readers that promote world cultures and discuss the issue of translating Early Readers from one language to another.

As this is the first book dealing with the topic of Early Readers, it is very valuable for both teachers and parents when it comes to teaching children how to learn independently. The editors have managed to gather essays that approach the common theme from different points of view and have divided them into special chapters, which make it very easy to find a particular subject.

The first two sections will be more interesting to people who want to learn what Early Readers are and how and why they are written, while the next two sections primarily deal with specific examples and descriptions of Early Readers. This is probably the more inspiring part of the collection for teachers and parents because it brings numerous examples of Early Readers and offers a variety of options for their practical use in class and at home. All of them are carefully evaluated and both the advantages and possible disadvantages of each book are explained.

While most of the chapters deal with the positive aspects of using Early Readers, there are also some that criticise them for containing made-up words, misspellings, and, surprisingly, they object to such aspects as nonsense and different kinds of wordplay.

The Early Reader in Children's Literature and Culture gives an interesting overview of this special genre, raising both theoretical and practical issues. The editors have achieved their goal of giving it the attention it needs. Besides, their book offers a sound foundation for further examination and discussion of these little books for early readers.

Dorja Anić 